\author{
N. S. Simanovych, Ye. V. Brytavskyi, M. I. Kutalova, V. A. Borshchak, Y. N. Karakis
}

Odessa I. I. Mechnikov National University, 42, Pastera Str; phone: 723-34-61

e-mail:ndl_lepikh@gmail.com.ua.

\title{
THE STUDY OF HETEROGENEOUS SENSITIZED CRYSTALS OF CADMIUM SULFIDE. PART I ABOUT CHARGE OF THE CENTERS RECOMBINATION
}

\begin{abstract}
The photovoltaic properties of CdS crystals with combined alloying have been investigated. An analytical expression for the dependence of the coefficient of damping of the intensities of exciting and quenching light has been received. For the first time the concentration of fast recombination centers has been estimated.
\end{abstract}

Charge status of S- and R-centers has been calculated. At the same time an exclusive method of solving the system of equations was created. Modulation of illumination-current characteristics with infrared light has been demonstrated.

Sensitization of semiconductors can be observed in that case if in the crystal, which already has effective centers of recombination, enter the same effective traps for carriers of one of the characters, preferably minor. Then, upon photoexcitation, due to the shortage of appropriate media, the rate of recombination is significantly reduced and the photocurrent is increasing.

This effect was first theoretically developed in the monograph A. Rose, by example, of cadmium sulfide. With well-chosen parameters, according to calculations of the author, the lifetime of the main carriers could grow up to five orders of magnitude. The concentration of recombination and sensitized centers $\sim 10^{15} \mathrm{~cm}^{-3}$ was used. They are named respectively the 1 st and 2 nd classes. The magnitude of the capture cross section for electrons and holes was taken to be equal

$$
\begin{gathered}
\mathrm{S}_{1 \mathrm{n}}=\mathrm{S}_{1 \mathrm{p}}=\mathrm{S}_{2 \mathrm{p}}=10^{-16} \mathrm{sm}^{2} ; \\
\mathrm{S}_{2 \mathrm{n}}=10^{-21} \mathrm{sm}^{2}
\end{gathered}
$$

The centers of the first class R. Bube called fast or S-centers ("Speed"), and the centers of the second class, respectively slow, due to the strongly different capture cross section, or R-centers ("Recombination"). In the present work, all three designations (class 1, fast, S-centers) will be used as synonyms.
The simultaneous existence in the sample of the fast and slow centers in detectable concentrations creates the conditions for effect, reversed to sensitizing, named infrared (IR) - absorption photocurrent. Upon excitation of such a crystal with its own light, and then with the IR illumination, the photocurrent may be reduced. This is due to the release of IR photons captured at the centers of the 2nd class cavities with the corresponding enhancement of the recombination of majority carriers. To estimate the damping was introduced the ratio $\mathrm{Q}$ which is equal to the change of the photocurrent relatively to the original values.

It should be noted that because it is determined not the current, and its relative (including little) change, significantly increases the sensitivity of the method to external influences (light, temperature, voltage). At the same time decreases the influence of unavoidable noise. Secondly, due to the peculiarities of alloying it is possible to create a single-chip sensors of different wavelengths, whereas for the own conductivity of the semiconductor it is not possible. Finally, while it is easily possible to create a spatially inhomogeneous sensitive system, it is not feasible on the basis of isotropic crystals.

Therefore, we chose the effect of infrared quenching of photocurrent as a research tool. In our opinion, this approach has several advantages.

First of all, if the investigated crystals sufficiently saturated with $\mathrm{S}$ - and $\mathrm{R}$ - centers, the distance between them is small. In this case, holes, embossed by IR light from the centers of slow 
recombination, after only a few broadcasts of the crystal lattice passed, will be taken to S-centers and immediately affect on the value of the flowing current. Moreover, if the S - and R-centers are distributed uniformly, the path length will be more or less standardized. In a typical situation, these processes are disguised with a scattering, accidental captures in traps, unauthorized channels of recombination, etc.

In addition, the specificity of IR-quenching allows to independently manipulate both parameters current forming their own light, and the intensity and spectral distribution of infrared light, solely responsible for the release of holes. The possibilities of infrared quenching allows to selectively use the light in certain wavelengths instead of the whole spectrum.

Finally, the effect of IR-quenching allows to highlight and to explore the mechanism of emission of carriers from one particular class of centers, whereas in the usual case we have to deal with a whole range of traps, the process of devastation which camouflage each other.

These features of the infrared blanking make it a sensitive and flexible method of studying the intricacies of the photoexcitation of the non-native speakers. In addition, the combined effects of the crystals allowsthe parametric control of the processes.

As a support of the semiconductor research was selected semiconductor single crystal cadmium sulfide. Its advantages are: firstly, high photosensitivity (fotoresponseis up to seven orders of magnitude) and comparative ease of application of electrical contacts and a significant coefficient of solubility for most legants. Secondly, the presence of sensitivized R-centers, which is typical for a relatively narrow class of substances. Finally, thirdly, it is a wide bandgap semiconductor $\left(\mathrm{E}_{\mathrm{g}} \sim 2,42 \mathrm{eV}\right)$, that allowed to carry out research in a wide range of wavelengths from 400 to $1600 \mathrm{~nm}$ with well-separated four sections surface, own, trapping of absorption and IR spectra. In some cases, such crystals are convenient to use as a model material.

The high sensitivity of cadmium sulfide accounts for $520 \mathrm{~nm}$ and corresponds well to the solar spectrum. This allows to use it not only in the laboratory but also under natural light to create sensors for various purposes.

The aim of this work is the study based on the effect of IR-quenching of photocurrent of the nuances of the processes occurring upon excitation of charge carriers from the bound in the conductive state in the crystals of cadmium sulfide with an unevenly distributed impurities.

\subsection{The dependence of the infrared quenching from intensities of exciting and quenching light}

The concentration of free carriers normally is expressed in the population of recombination centers of 1 st and 2 nd classes, which themselves vary at different levels of the exciting and quenching light. This considerably complicates the calculations, making them less accurate and, in fact, not acceptable in practice. The expression for the explicit form of $Q\left(L_{e} ; L_{q}\right)$ in the literature we could not find.

While illuminating the crystals only with its own light with intensity $L_{e}$ the concentration of free electrons $n$ (e) (when the absorption coefficient $\alpha$ and light of its own quantum output $\beta$ ) is given by

$$
n(B)=\alpha \beta L_{e} \tau_{n l .}
$$

In (1.2) taken into account that the recombination is carried out mainly through the S-centers and, consequently, the life-time $\tau_{n l}$ is determined by this channel.

At sufficiently high intensities of the exciting light value $\tau_{n 1}$ does not depend on its intensity, since the difference between the concentrations of free carriers $(n-p)$, is equal to the change in the filling of recombination centers, is much less than the concentration of these centers. So on the chart of lux-ampere characteristics (LAC)is observed two sections with different slopes at high and low intensities of exciting light (tab at Fig. 1.1).

The change of formation mechanism of the photocurrent and, accordingly, the slope of a plot of LAC occurs when the number of incident photons becomes comparable with the concentration of recombination centers. This is due to the ratio 
of the concentration of incident photons and fast recombination centers. When the light intensity is small, the number of absorbed photons, and hence the number of exempt carriers is less than the concentration of fast recombination centers. In this situation they can effectively contribute to the recombination of electrons and holes. For a large light fluxes, the number of photoexcited carriers is larger than the number of centers where they could recombine. S-centers can not cope with increasing concentration of free electrons and holes and the recombination rate is limited only by the throughput capacity of the centers, regardless of the total number of carriers. The situation is stabilizing. If so, then the inflection point on the LAC (in our case $\mathrm{L}_{0 \mathrm{e}}=3,2 \mathrm{~lx}$ ) can be estimated by order of magnitude the concentration of S-centers.

The mechanical equivalent of light $\mathrm{A}=0.0016$ and a photon energy equal to the width of forbidden zone of CdS $E_{g}=2,42 \mathrm{eV}$, we obtain the number of photons $N_{f} \stackrel{g}{=} L_{0 e} / E_{g}=$ of $2.88 \cdot 10^{17} \mathrm{~s}^{-1} \mathrm{~m}^{-2}$ in the used light flux. In a typical specimen dimensions $1 \times 1 \times 1,2 \mathrm{~mm}$ from this thread on its front surface we have $N_{f}=3,46 \cdot 10^{11} \mathrm{~s}^{-1}$ of photons. They are all absorbed in the crystal volume of $1.2 \cdot 10^{-3}$ $\mathrm{sm}^{3}$. Therefore, the volume concentration of the recombination centers $N_{r}$ is equal to the number of photons evenly distributed in this volume, will be $N_{r}=2,88 \cdot 10^{14} \mathrm{sm}^{-3}$. The obtained value of $3 \cdot 10^{14}$ $\mathrm{sm}^{-3}[1,2,3]$, we consider as the lower limit of the doping impurity recombination. Because of the capture cross section for holes at the centers of the 1 st and 2 nd classes differs by five orders of magnitude, then about as many different of rates of recombination on them. Therefore, it can be argued that the value almost entirely refers to the concentration of fast recombination centers. Note that this value Rose A. operates without any justification.

The proposed method is innovative. Up to the present time for S-centers was determined with cross-section grips and, with certain reservations, the energy of activation. In any case, the zone charts show these levels closer to the conduction band. The question of their concentrations remained open.

When you turn on infrared light with corresponding energy redistribution of the holes oc- curs, and hence the rate of recombination through the centers of I-st and II-d class changes. Recombination throw the $\mathrm{R}$ - centers is getting even less, and throw the $\mathrm{S}$ - centers increases. Therefore, the formula $f=q_{n 1}^{\prime}$ remains valid.

In each act of recombination interacts with one carrier of both signs, so the rate of recombination of electrons and holes to the same level are equal $q_{n 1}^{\prime}=q_{p 1}^{\prime}$. Then you can write

$$
\begin{aligned}
f & =q_{p 1}^{\prime}, \\
\text { where } & q_{p 1}^{\prime}=\frac{p+\partial p}{\tau_{n 1}}
\end{aligned}
$$

It is considered that under the action of infrared light, the concentration of holes at the centers of the second class decreased with $\partial P$ and increased respectively at the same concentration of holes in the valence band.

If in the unit of time the quantum of quenching light $L_{q}$ drops on the crystal, then in unit of volume will be absorbed $\alpha^{\prime} \cdot L_{q}$ quantums, where $\alpha$ ' - is the fraction of the slow recombination centers which was interected with light. Hence the additive in the concentration of free holes

$$
\partial p=\alpha^{\prime} \cdot L_{\dot{q}} \cdot \tau_{P 0}
$$

where $\tau_{p 0}$ - is the lifetime of free carriers. Since the recombination of the holes also is mainly carried out through the $\mathrm{S}$ - centers, use

$$
\partial p=\alpha^{\prime} \cdot L_{q} \tau_{P 1}
$$

For large excitation level with its own light $\mathrm{p}=\mathrm{n}$ and the expression (1.3) with (1.4) and (1.5) takes the form

$$
\begin{aligned}
& \alpha \cdot L_{e}=\frac{n}{\tau_{p 1}}+\alpha^{\prime} \cdot L_{q} \\
& n_{(g, q)}=\left(\alpha \cdot L_{e}-\alpha^{\prime} \cdot L_{q}\right) \cdot \tau_{\rho 1}
\end{aligned}
$$

Formula (1.8) describes the dependence of the concentration of free electrons from the concurrent intensities of exciting and quenching light.

If the intensity of infrared light is not very big, then $\partial p<p_{r 2}$. Population density in the holes of 
the R-centers does not change very much, and the value $\tau_{p l}$ does not depend from the infrared light.

Expressions (1.2) and (1.8) allow to obtain the dependence of IR-quenching from intensities of used light fluxes [4]:

$Q=\frac{I_{f(e)}-I_{f(e, q)}}{I_{f(e)}}=\frac{n_{(e)}-n_{(e, q)}}{n_{(e)}}=\frac{\alpha \cdot L_{e} \cdot \tau_{n 1}-\left(\alpha \cdot L e-\alpha^{\prime} \cdot L q\right) \cdot \tau_{p 1}}{\alpha \cdot L e \cdot \tau_{n 1}}$

or after transformations:

$Q\left(L_{q} ; L_{e}\right)=\left[\left(1-\frac{\tau_{p 1}}{\tau_{n 1}}\right)+\frac{L_{q}}{L_{e}} \cdot\left(\frac{\alpha}{\alpha^{\prime}} \cdot \frac{\tau_{p 1}}{\tau_{n 2}}\right)\right] \cdot 100 \%$

Formula (1.9) shows the dependence of the optical quenching from the intensities of exciting and quenching light. It should be noted that this relation is valid for small intensities of quenching light and for high levels of photoexcitation, when you can not take into account the change of populations of recombination centers.

The total experimental results of the behavior of the coefficient of quenching $Q$ with the change of quantities of the light fluxes are shown at Fig. 1.1.

As a reference for them to take the curve 2, measured at the same intensities of its own and quenching lights, as in the case 1.1a and case $1.1 \mathrm{~b}$. On the left part of figure 1.1a, is shown how the value changes upon variation of the excitation light at a constant quenching. At Fig.1.1b, on the contrary, a reference curve was fixed the intensity of the excitation light and was changing of quenching light.

All graphs on Fig.1.1 received in steady-state conditions. In each point was kept sufficiently long relaxation (up to 20 minutes) to avoid the processes described in $[5,6,7]$. Relaxation characteristics of crystals will be discussed in part II.

First of all, note that any combinations of the intensities of short-wave maximum (Fig.1.1) was far below than long-wave $[3,8]$. This is due to thermal swap for the captured carriers. Due to the absorption of the phonon, one part of the holes from basic R-level moves to an excited R'. And the population of these levels with holes identifies relevant peaks. For this reason, as can be seen from figures $(1.1 \mathrm{a}, \mathrm{b})$, to changes in the intensities of each light, the more sensitive is the first maximum (short-wave).
As can be seen from Fig. 1.1b, the smaller the intensity of the quenching light, $L_{e}=$ const the smaller is the value $Q$. Moreover, for smaller intensities of the self-excitation it was manifested brighter. Experimentally was managed to create a situation when shortwave maximum disappeared completely $[9,10]$.

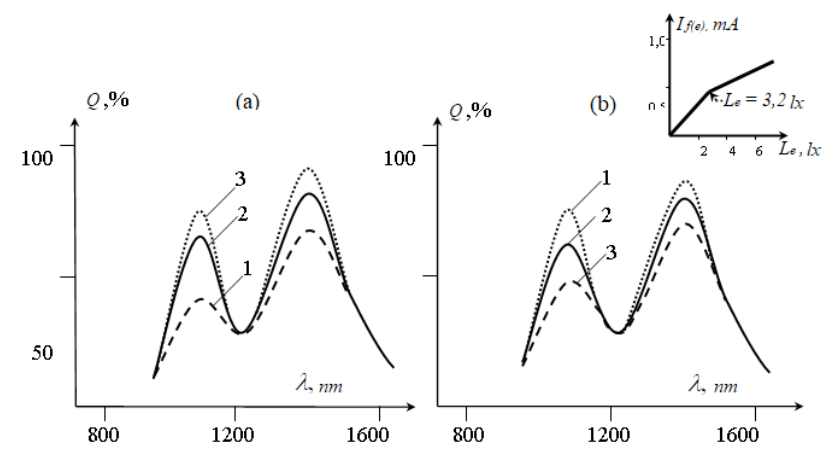

Fig. 1.1. The dependence of the value of quenching from the intensities of used light. a) $L_{q}=$ const, $\left.\mathrm{L}_{\mathrm{e} 1}>\mathrm{L}_{\mathrm{e} 2}>\mathrm{L}_{\mathrm{e} 3} ; \mathrm{b}\right) \mathrm{L}_{\mathrm{e}}=$ const, $\mathrm{L}_{\mathrm{q} 1}>\mathrm{L}_{\mathrm{q} 2}>\mathrm{L}_{\mathrm{q} 3}$. The experimental points are not plotted in order not to clutter the drawing.

At the same time, with the same intensity of quenching light (see Fig.1.1 a), with decreasing excitation $L_{e}$, the value of the coefficient of quenching increases. Moreover, this increase we saw more if used intensities $L_{q}$ were negligible.

These experimental behaviors $Q\left(L_{e} ; L_{q}\right)$ confirm the validity of formula (1.9).

\subsection{Critical modes of lighting crystals with infrared quenching of photocurrent}

Formula (1.9) shows the dependence of the optical quenching from the intensities of exciting $L_{e}$ and quenching light $L_{q}$. It should be noted that this relation is valid for relatively low intensities of quenching light and high levels of photoexcitation, when you can not take into account the change of populations of recombination centers.

As a rule, if the effect of the quenching of the photocurrent is clearly distinguishable, in all combinations of the intensities the short-wave maximum quenching (1080-1100 nm) was far below that long-wave (1380-1400 nm). This is due to thermal swap for the captured carriers. Due to the absorption of phonons, the part of 
holes from the basic R-level, moves to an excited R' (discussed in part III). And the population of these levels with holes identifies the relevant peaks. For this reason, for the changes of the intensities of each light the more sensitive is the first maximum (high).

Among the restrictions imposed in the derivation of formula (1.9), was that all holes, embossed by light levels $\mathrm{R}-\mathrm{R}$ ' remain in the valence band and enhance the capture on $\mathrm{S}$-centers. Generally speaking, this is incorrect. The capture of cross section of holes S - and R-centers are equal. However, just photoexited hole spatially is near R-centre and probably will be again captured [8]. Similar, probably multiple, oscillations did not occur at fixed external parameters and lead to useless absorption of photons of infrared light. It is obvious that this process can camouflage the dependence of the intensity of the infrared light. More this effect will be discussed in part II.

Under the critical light levels, as exciting and quenching light, we will understand these light beams, when on the spectral distribution of coefficient of quenching are not only mentioned in section 1.1 quantitative change, but there is a quality changes[10].

As was noted above that because of the growth of intensity of self-excitation and reducing of the flow of infrared radiation the value of quenching in accordance with the formula (1.9) decreases. When a critical ratio of these intensities, it is possible when on the curve of spectral distribution $Q(\lambda)$ completely disappears shortwave maximum, then the long-wave still is present. Formula (1.9) for this case is not applicable because violation of tolerance limits aremade at its conclusion.

The processes in this case can be explained as follows. The smaller the value $L_{q}$, the less infrared photons knock out holes from R-centers. Accordingly, fewer of them come to the fast recombination centers and the decline of majority carriers - electrons becomes less. It is this relative reduction estimates (using current) the value of the coefficient $Q$. The greater the intensity of its own light and, accordingly, the initial concentration of free electrons, the less is noticeable their decrease in recombination. First and foremost, from graphic is disappearing shortwave maximum $Q(\lambda)$, as it relates to the liberation of holes from the basic state of R-centers, where the concentration of charge is less because of thermal pumping to R'- states.

The reverse situation (see Fig. 1.2) - maximum flow of infrared light and extremely high levels of self-photoexcitation - we observed not previously described in the literature, the phenomenon of the disappearance of the long-wave maximum quenching of the photocurrent $(1380-1400 \mathrm{~nm})$, whereas shortwave maximum $Q(\lambda)$ in the region of $1080-1100 \mathrm{~nm}$ was still remained.

The limit levels of exposure were determined by the capabilities of the experimental unit. In the area of maximum photosensitivity of the sample $(520-530 \mathrm{~nm})$ intensity of monochromatic light provided the illumination of order $5-6 \mathrm{~lx}$.

In our case, the determining impact provide the mechanisms of formation of maximums $Q(\lambda)$ by themselves. For the reasons that were described above, due to the redistribution of the concentration of trapped holes, the shortwave maximum of quenching $(\sim 1100 \mathrm{~nm})$ lower than the wavelength must to disappear first in suboptimal ratio of the intensities of clipping.

Abnormal view of curve $Q(\lambda)$ with a missing long-wavelength maximum $(\sim 1380 \mathrm{~nm})$, we explain in the following way. In accordance with the formula (1.9) the value of coefficient $Q$ does not depend on the intensity $L_{q}$ and on result $L_{q} \beta$, including the value of the quantum yield. The authors [3] have noted that for some ratios of intensities of light fluxes, the magnitude of the quantum yield for infrared radiation in the samples with R-centers can quickly decrease. Experimentally were recorded the values of the or$\operatorname{der} \beta^{\prime}=0,026 \div 0,072$ [8]. At such small values the decrease of $\beta$ ' can be decisive even at relatively high values of $L_{q}$ in the numerator of (1.9).

To explain the dependence of $Q(\lambda)$ for this case we propose the following mechanism. When we are illuminating by light with a wavelength corresponding to the activation energy of $\mathrm{R}$ ' - centers, the number of seats available to them increases. In this case the outflow of thermally excited holes from R-levels should increase. In turn, this leads to an increasing of seats available at those levels. As a result, the repeated captures of holes to R' centers are increasing, and the quantum yield for infrared radiation is even lower. 
Note that the described effect, obviously, can be carried out for each set temperature only in a narrow range of ratios between the existing concentration of R-centers and used its own intensity of light and infrared radiation. Analysis is easier to carry out under the condition when only the intensity of light of its own relatively changes according to the other three fixed parameters.

If your exiting is too great, in the $V$-zone is a large number of free holes. Additional charge, embossed by IR-radiation from R-centers, can not significantly change their concentration, and thus the flowing current.

Besides, R-centers are heavily populated by holes (probably, even $p_{r} \approx N_{r} ; p_{r}, \approx N_{r}$ ). Relatively small changes caused by IR photons are not able to affect the existing ratio of concentration of the charges on the centers. Moreover, the resulting empty spaces will be filled with holes from the valence band.

On the contrary, if the intensity of its own light is not large enough concentration of localized holes at the centers of class II will be lowal. In this case, before the activation of the IR light on the R-centers are a significant number of places with blank holes. The appearance of IR excitation can not make any noticeable changes in their number, and hence the balance of processes of capture-emptying.

Held arguments correspond to movement along the line $\mathrm{AB}$ schematic figure 2. Area 1 at Fig. 1.2 is the magnitude of the intensities when the standard mechanism of A.Roseis. In such conditions were starred family of graphs $Q(\lambda)$ Fig.1.1, and such light fluxes obtained formula (1.9).

Its output was simplify by demanding conditions $L_{q} \uparrow>L_{e} \uparrow[4]$, i.e. when a significant number of photons as their own get on the sample, and infrared light, and quenching - more. For this reason, in region 2 Fig.1.2 the formula (1.9) are not applicable.

The effect of quenching may not be implemented here immediately for three reasons:

I. First, when there is small own excitation $\left(L_{e} \rightarrow 0\right)$ the number of pairs of free nonequilibrium carriers is less than can recombine via $\mathrm{S}$ centers;

II. Second, minor activation of holes from Rcenters $\left(L_{q} \rightarrow 0\right)$ is almost completely masked by the processes of dissipation, captures in traps, etc. These holes practically do not reach S centers;

III. Finally, the small number of extra holes that reach the centers of quick recombination, causing a slight decline of majority carriers electrons - and, therefore, virtually do not impact on the change of the photocurrent.

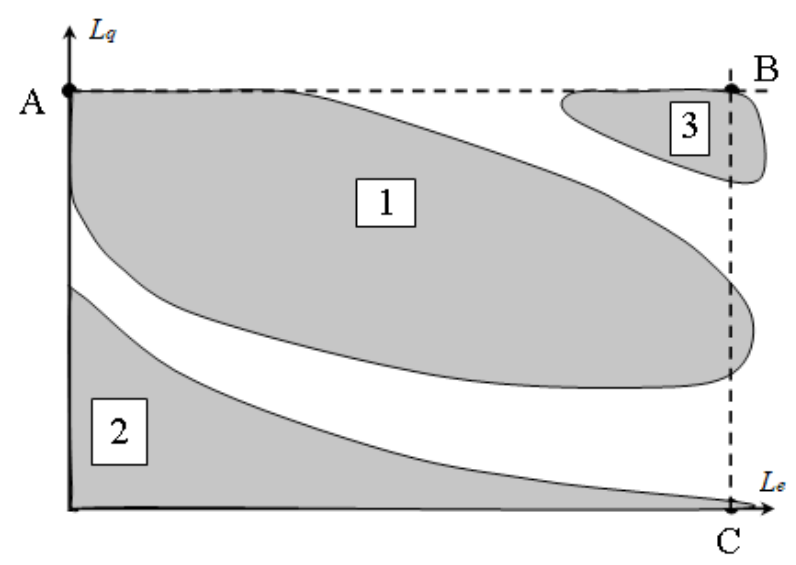

Fig. 1.2. Field of possible ratio of the intensities of exciting and quenching light; 1 - region of existence of the effect of IR-quenching of photocurrent; 2 the area of intensity when extinction does not occur; 3 - area where you may watch the abnormal effect of quenching. Unpainted areas are transitional between these regions.

Forcompleteness, wewillhold the consideration in which area 3 Fig. 1.2 can be accessed along the line CB. That is, when extremely high level of self-excitation is recorded and the infrared flow gradually increases.

For small values of $L_{q}$ quenching does not occur in virtue of the third condition for region 2 . When averages $L_{q}$ quenching although appears, but slightly. This corresponds to the limit situation of the region 1 Fig 1.2. Finally, for large intensities, comes into force the mechanism of the anomalous absorption, described above.

The maximums of quenching dependence $Q(\lambda)$ behave differently. The short wavelength peak in the $1100 \mathrm{~nm}$ may increase at the expense of complete emptying of the ground state of R-centers. Long-waved infrared (1400 $\mathrm{nm}$ region) can not appear even under these conditions because of the low value of quantum yield. Photoexited ones from $\mathrm{R}$ '-states of the hole remain in the area 
of R-centers at the expense of repeated seizures and does not contribute to recombination at the S-centers.

Thus, the peculiarities of interaction of infrared radiation with the centers of class II impose limitations on the applicability of the expression $\mathrm{Q}\left(L_{e}, L_{q}\right)$, and the relative magnitude of the maxima of the extinction.

\subsection{About charge state of the centers of slow and fast recombination}

Model of infrared quenching of photocurrent Bube-Rose based on the existence in the crystal the recombination centers of the two classes.

R-centers are external impurity in the sample, most likely copper in the cadmium sublattice. To get to the crystal this impurity can only in the neutral charge state. If this is a trap for holes, then it has two states: neutral and positively charged after the capture of holes. It also points to the capture cross section for holes $10^{-16} \mathrm{sm}^{2}$. Such values of cross sections are typical up for grabs in a neutral trap.

However, the capture cross section for electron $-10^{-21} \mathrm{sm}^{2}$ is the usual for grabs in a repulsive center. At the moment of electron capture, the center is already charged negatively. In this case, it is the acceptor. He gave the hole and is charged negatively. For holes it is the attractive center now and should have a corresponding capture cross section $\sim 10^{-12} \mathrm{sm}^{2}$, what is not observed experimentally. On the contrary, it is established that R-centers after the capture of an electron does not possess a repulsive Coulomb barrier. These are singly charged acceptors and the electron capture occurs with a neutral center.

For holes found that with decreasing temperature the possibility of internal transfer of these carriersdecreasesin the R-centers, what is very unusual to capture at the charged centre, besides having a system of intermediate states.

Thus, there is a contradiction - there are arguments that the R-centers are either in the neutral and positively charged or neutral and negatively charged, both could not be madeat the same time. We have to assume that these states alternate, with the presence of at least one intermediate stage. A simple scheme, when a neutral acceptor would give a hole, and then captured electron with the subsequent recombination of it with the new spare hole, would require that at the final stage the hole was captured on a doubly negatively charged center, what is also not observedin the experiment.

Note that it is possible that the ensemble of Rcenters consists of several groups: it may be copper in the cadmium sublattice of $C u_{C d}$ or negatively charged center of the silver in the cadmium sublattice $A g_{C d}^{-}$, or even a complex neutral conglomerate of charged sulfur vacancies of sulfur and cadmium $\left(V_{S}^{2+}+V_{C d}^{2-}\right)$.

As for the S-centers, data on their charge state do not exist to the present time. Make any reasonable assumptions based on a simple analysis of the capture cross section for electrons and holes is impossible. It is the equality of these cross sections in a model A. Rose is doing these centers an effective channel of recombination. But in this case, if in initial state, these centers were neutral, then after the hole capture, they become positively charged. With equal probability, after the capture of an electron, they acquire a negative charge.

A. Rose model does not consider the order of the carrier capture on S-centers. In literature data about the scenario of these processes is not affected. Of the characteristics of the field drift of the centers of quick recombination at a known applied voltage polarity concluded that they are positively charged. For a long time the samples were kept under conditions of the applied field. Then were measured local probe characteristics of tactile sensing. It was discovered, the enhancement of IR-quenching of photocurrent in the nearcathode region.

At the same time centers of quick recombination are attributed to the properties of electronic traps. In this case, they can be either neutral or carry a negative charge. The question remains open and requires further study.

We attempt to resolve some of these incorrectness [11].

The interaction of charge carriers with local centers in a two-level model of recombination Bube-Rose is described by the equations: 


$$
\begin{gathered}
S_{n 1} v p_{1} n=S_{p 1} v n_{1} p \\
S_{n 2} v p_{2} n=S_{p 2} v n_{2} p \\
n=f \tau_{n}=\frac{f}{S_{n 1} v p_{1}+S_{n 2} v p_{2}}
\end{gathered}
$$

Here $S_{i j}$ - are the corresponding capture crosssections of electrons and holes at the centers of the first and second classes; $\mathrm{p}, \mathrm{n}$ - concentrations of free charge; $v$-speed of thermal motion; $p_{1}$, $\mathrm{p}_{2}, \mathrm{n}_{1}, \mathrm{n}_{2}-$ concentrations of electrons and holes captured in the centers of fast and slow recombination, $f$ - the intensity of the photoexcitation; $\tau_{\mathrm{n}}$ - is the lifetime of the main carriers.

The first two of these equations represent the equality of the rate of capture of holes and electrons respectively in S - and R-levels, the third is the condition of non-accumulation of charge. This assumes that the sample is sufficiently high resistance, and the intensity of the light, and with it the intensity of the photoexcitation is sufficiently large. Under these conditions, concentrations, which are included in the equations (2.1)-(2.3) are non-equilibrium carriers, and the lifetime of the main carriers obeys the expression (2.3).

The number of variables in the formulas (2.1) - (2.3) can be reduced given the fact that for large photoexcitation intensities, the number of free charge carriers is comparable or higher than the concentration of recombination centers. An idle trapsare not left. Since the recombination center, by its nature, may be occupied either by an electron or a hole, then is true

$$
\begin{aligned}
& n_{1}=N_{1}-p_{1} \\
& n_{2}=N_{2}-p_{2}
\end{aligned}
$$

where $N_{1}$ and $N_{2}$ - total concentration of $\mathrm{S}$ - and $\mathrm{R}$-centers, respectively.

To solve the system of equations $(2.1)-(2.5)$ should be closed by the condition of electroneutrality. It's kind depends on the allowed charge states of the centers of the I-st and II-d classes. There are four possible options:

If R-centers are charged positively, the equation of electroneutrality is representable for posi- tively charged S-centers

$$
n=p+p_{1}+p_{2},
$$

or for negative $\mathrm{S}$-centers

$$
n+n_{1}=p+p_{2}
$$

Taking into account (2.4) the expression (2.7) can be rewritten as

$$
n=p+p_{1}+p_{2}-N_{1}
$$

If R-centers are charged negatively, the corresponding electroneutrality conditions will have the form for positively charged S-centers

$$
n+n_{2}=p+p_{1},
$$

for negatively charged S-centers

$$
n+n_{2}+n_{1}=p
$$

Taking into account (2.4) the expression (2.8) becomes

$$
n=p+p_{1}+p_{2}-N_{2} .
$$

And taking into account (2.5) and (2.6) the expression (2.9) takes the form

$$
n=p+p_{1}+p_{2}-N_{1}-N_{2}
$$

For convenience, the condition of electroneutrality for all possible cases collected in table 2.1.

Without going into details of the processes, we have carried out calculations for all four systems of equations $(2.6 a, b, c, d)$ so $(2.1)-(2.3)$ with (2.4), (2.5).

Unknown are $n, p, p_{1}$ and $p_{2}$. Since the system of four linear equations are with four unknowns, all of them have solutions, and these solutions are single-valued and unique.

The case of negatively charged R-centers

It was found that for negatively charged Rcenters the studied system of equations has no positive solutions when you use the equation of 
electroneutrality in the form of (2.6b) and (2.6d).

For example, when negatively charged levels of the second class and the positively charged centers of the first class, in terms of

$$
f=10^{15} \mathrm{sm}^{-3} \mathrm{~s}^{-1} ; N_{1}^{+}=N_{2}^{-}=10^{15} \mathrm{sm}^{-3},
$$

the system of equations (2.1)-(2.3),(12.6d) has the solution [12]:

$n=-1,005 \times 10^{15} \mathrm{sm}^{-3} ; p=4,988 \times 10^{7} \mathrm{sm}^{-3} ;$ $p_{1}=-4,963 \times 10^{7} \mathrm{sm}^{-3} ; p_{2}=-4,987 \times 10^{12} \mathrm{sm}^{-3}$. The error function (see below) in this case was $F=$ 0,0000077 .

I.e. negative concentrations appear. This means that under the current model, the centers of slow recombination of negative charge can not bear. This conclusion is in good agreement with the value of the capture cross section for holes on these centers. The question of how the value of capture cross sections for electrons form for them remains open.

Table 2.1

Four variations of the charge States of $R$ - and S-centers

\begin{tabular}{|c|c|c|c|}
\hline Local levels & \multicolumn{3}{|c|}{ R-centers } \\
\hline \multirow{3}{*}{ S-centers } & charge & + & - \\
\hline & + & $\begin{array}{c}n=p+p_{1}+p_{2} \\
(2.6 \mathrm{a})\end{array}$ & $\begin{array}{l}n=p+p_{1}+p_{2}-N_{2} \\
(2.8) \rightarrow(2.6 c)\end{array}$ \\
\hline & - & $\begin{array}{cc} & n=p+p_{I}+p_{2} \\
-N_{I} & \\
& (2.7) \rightarrow(2.6 \mathrm{~b})\end{array}$ & $\begin{array}{ll} & n=p+p_{1}+p_{2}-N_{I}- \\
N_{2} & \\
& (2.9) \rightarrow(2.6 \mathrm{~d})\end{array}$ \\
\hline
\end{tabular}

Case of positively charged R-centers

For positively charged R-centers and positively charged S-centers, the working system of equations after transformation has the form:

$$
\begin{gathered}
n p_{1}=p\left(N_{1}-p_{1}\right) \\
n p_{2}=A p\left(N_{2}-p_{2}\right) \\
B=A n p_{1}+n p_{2} \\
n=p+p_{1}+p_{2}
\end{gathered}
$$

where $A=\frac{S_{p 2}}{S_{n 1}}=10^{5} ; \quad \mathrm{B}=\frac{f}{v S_{n 2}}$.In all cases the value $v$ was equal $10^{7} \mathrm{sm} / \mathrm{s}$.

Parameters in the system of equations (2.10) (2.13) are $N_{1}, N_{2}$ and $f$. Each of these variables can take values from a wide range of numbers from
$10^{12}$ to $10^{18}$. Therefore, we used the following tactics: concentration of S-centers fixed at the level of $10^{15} \mathrm{sm}^{-3}$, regarding it as the argument value $N_{2}$ has changed from $10^{14}$ to $10^{16} \mathrm{sm}^{-3}$. The system of equations was solved several times for different levels of photoexcitation $f=10^{14} ; 10^{15}$; $10^{18} \mathrm{sm}^{-3} \mathrm{~s}^{-1}$ (i.e. less, equal to, and a lot more than fixed concentration of fast recombination centers). The asymmetry of the spread of selected values of $f$ with respect to $N_{1}$ is due to the fact that the original system of equations (2.1)-(2.3) is written for large levels of photoexcitation.

From equation (2.12)

$$
p_{2}=\frac{B}{n}-A p_{1} .
$$

From equation (2.10)

$$
p=\frac{n p_{1}}{N_{1}-p_{1}} .
$$

Dividing (2.10) by (2.11) we get

$$
\frac{p_{1}}{p_{2}}=\frac{N_{1}-p_{1}}{A\left(N_{2}-p_{2}\right)}
$$

from where

$$
p_{2}=\frac{A N_{2} p_{1}}{N_{1}+p_{1}(A-1)}
$$

Joint solution of (2.8) and (2.5) gives

$p_{1}{ }^{2} A(A-1)+p_{1}\left[A\left(N_{2}+N_{\nu}\right)-\frac{B}{n}(A-1)\right]-\frac{B N_{1}}{n}=0$. form

The solution of this quadratic equation has the

$$
p_{1}=\frac{-D+\left[D^{2}+4 A(A-1)\left(\frac{B}{n}\right) N_{1}\right]^{\frac{1}{2}}}{2 A(A-1)}
$$

in which

$$
D=\left[A\left(N_{2}+N_{l}\right)-\frac{B}{n}(A-1)\right] .
$$

The "-" sign before the root in (2.18) is discarded because it leads to $p_{1}<0$. 
Equation (2.14),(2.15),(2.18) after substitution in (2.13) provide an equation with one unknown variable $-n\left(N_{2}\right)$ :

$$
n=\frac{n p_{1}}{N_{1}-p_{1}}-p_{1}(A-1)+\frac{B}{n},
$$

in which, for the sake of saving accounts the value of $p_{1}$ have not been painted, in accordance with the formula (2.18).

It is obvious that the resulting expressions are too cumbersome for analysis. Since after substituting for $p_{I}(n)$ structure of the expression (2.19)

has the form $f_{l}\left(n+\frac{1}{-}\right)=f_{2}\left(n+\frac{1}{1}\right)^{1 / 2}$, finally, one should expect the equations of at least fourth degree relative to $n$. Moreover, the coefficients in this equation may vary up to 15 orders of magnitude. That is the complexity of solving the given system of equations is probably the reason why such analysis was not previously done.

Us an algebraic way to solve the system of equations (2.10) - (2.13) were discarded, and instead applied such an artificial technique.

The value of $n$ is set arbitrarily. In accordance with the equation (2.18) is determined by the value $p_{r}$. Knowing it and $n$, the formulas (2.14) and (2.15) are determined by the numerical value of $p_{2}$ and $p$. Then all four numbers are substituted in the original system of equations, and determines the error function [see (2.10) - (2.13)]

$$
F=\frac{p\left(N_{1}-p_{1}\right)}{n p_{1}}+\frac{A p\left(N_{2}-p_{2}\right)}{n p_{2}}+\frac{A n p_{1}+n p_{2}}{B}+\frac{p+p_{1}+p_{2}}{n}-4
$$

Remains, fingering $n$, to minimize the error function. Four introduced into the formula (2.20) to the exact solution correspond to a value of $F$ which is equal to zero.

The peculiarity of function (2.20) is that it uses not the traditional difference of the left and right parts of the corresponding equations, and the quotient of their division. This is due to the fact that in the first three equations of system (2.10) $-(2.13)$ are the products of the concentrations. In this case, the difference of the left and right side of equation (2.13) will be much smaller (up to 15 orders of magnitude)than the remaining contributions to the error function, being at the level of machine zero. Namely, in this equation the characteristics of the charge state of the local centers are inherent. In addition, this approach eliminates the need to do the sign of the error in each of the equations. The advantage of the proposed method is in the simultaneous receipt of all the unknown quantities.
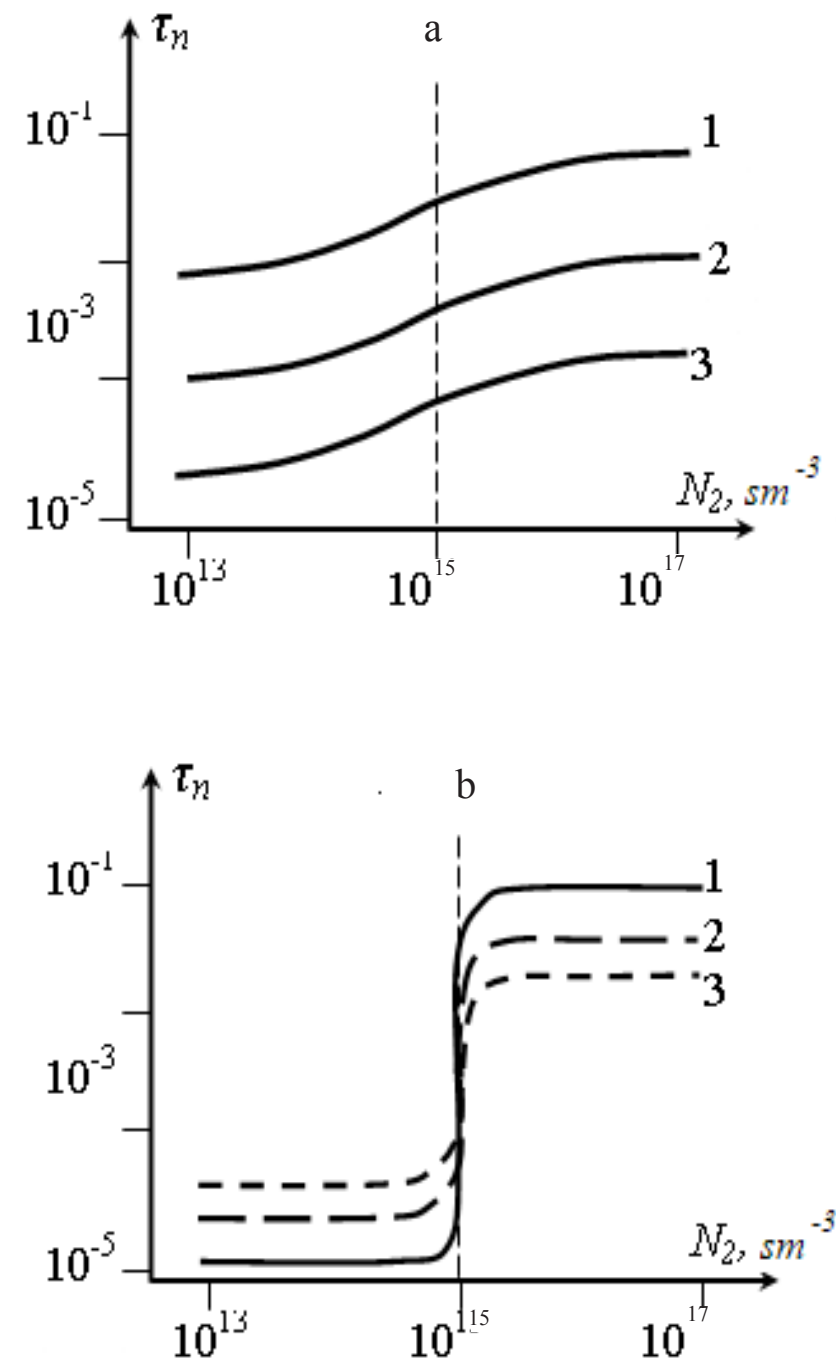

Fig. 2.1. The change of the lifetime of electrons when the concentration of $\mathbf{R}$-centers for levels of photoexcitation: $1-10^{14}, 2-10^{15}$ and $3-10^{17} \mathrm{sm}^{-3} \mathrm{~s}^{-1}$. A - the calculation was performed for positive, $B$ - for negatively charged centers of first grade.

The value of tactile sensing, we evaluated according to the change of the lifetime of the main carriers, the value of which had counted the fill level hole centers of the I-st and II-d classes: 


$$
\tau_{n}=\frac{1}{S_{n 1} p_{1} v+S_{n 2} p_{2} v}
$$

The results of the calculations [12,13] are shown in Fig.2.1A. It is seen that if the centers of both classes are positively charged, responsivity starts at the concentration of R-centers by about two orders of magnitude below than the concentration of S-centers. Regardless of the level of photoexcitation the value of the lifetime increases by about two orders of magnitude in the case when the concentration of R-centers also increases by two orders of magnitude higher than the concentration of S-centers.

The dotted line in Fig. 2.1 shows the concentration of S-centers. As a result of the problem solution at our disposal is just as the concentration $-N_{l}$, and the concentration of holes in centers of quick recombination $-p_{l}$, it is possible to determine directly the proportion of centers that captured positive charge. Depending on the lighting conditions $f$ and the concentration of centers $N_{2}$, value $\frac{p_{1}}{N_{1}}$ is amounted to $1-3 \%$. And even such S-centers in accordance with Fig. 1.1 can provide an increase in $\tau_{n}$ only several orders of magnitude. This is a weak and ineffective channel of tactile sensing. Nevertheless, it exists and is able to make some adjustments to the painting processes. Especially on the lower border of the governing parameters - at low levels of photoexcitation and low concentrations of the centers of the II-d-class - when the mechanism of tactile sensitizing of A. Rose (see Fig.2.1) are not yet included.

For the case of "positively charged R-centers

- negatively charged S-centers" the defining system of equations in accordance with (2.10) (2.12), (2.6d) has the form

$$
\begin{gathered}
n p_{1}=p\left(N_{1}-p_{1}\right) \\
n p_{2}=A p\left(N_{2}-p_{2}\right) \\
B=A n p_{1}+n p_{2} \\
n=p+p_{1}+p_{2}-N_{1}
\end{gathered}
$$

From equations $(2.10)-(2.13)$ they formally differ only in the last term in the fourth equation. However, the result is thus radically different.

Note the additional difficulty posed by the fact that the area $N_{2} \approx N_{1}$ the decision was stochastic - by changing the concentration in the second decimal place the value of lifetime was changed to five orders of magnitude (see Fig.2.1b). It had to take into account when choosing the step with which the calculations were increased and the concentration of centers of the second class.

The method of calculation was used the same as that which is described above. The results are shown at Fig. 2.1b. As experimentally quite well established, that in the sensitized cadmium sulfide lifetime of majority carriers changes by $4-5$ orders of magnitude, from the comparison of figures $2.1 \mathrm{a}$ and $2.1 \mathrm{~b}$ it follows that such a change can only be the case if the levels of the 1st class are negatively charged - are nonequilibrium electrons which are captured by neutral centers. The equation of electroneutrality is given by (2.6b).

Note that a significant sensitizing should be expected only for relatively small levels of exposure. With the increasing intensity of the photoexcitation of the upper part of the graph when $N_{2} » N_{1}$ is downward sloping, whereas the lower part under the $N_{2} \ll N_{l}$, moves towards it. As a result, the jump in the value of the lifetime after tactile sensitizing is a lot less. The effect of tactile sensitizing is concealed. This receives a natural explanation if we consider that at high rates of photoexcitation the carrier concentration is high. Introduction of the sensitized impurities of the same concentration is not able to increase it significantly.

In addition, it was found that the system of equations (2.1) - (2.3) - plus one of the conditions of electroneutrality (see table 2.1 ) are very sensitive to the last term in (2.6a) - (2.6d). Value when the system has physically meaningful solutions, i.e. when the principal features of the quenching appear, is about the order of $10^{15} \mathrm{sm}^{-3}$. This can be a value of concentration $N_{1}$ in the formula (2.6b) or $N_{2}$ in the formula (2.6b), or their sum $N_{1}+N_{2}$ in the formula (2.6d) (see table 2.1). Note that the 
order of magnitude was applied by A. Rose without comment. Because the description of tactile sensitizing was performed polyfermenticus and the condition of electroneutrality does not apply, there is a problem with the fetishization of that number. As a result of our consideration, was revealed the special properties of concentrations of centers of fast and slow recombination.

In the field of used values of the intensities of photoexcitation at a concentration of recombination centers is less than $10^{15} \mathrm{sm}^{-3}$ tactile sensitizing does not occur at all. When this limit is reached (first column, first row of the table 2.1) sensitizing is possible, but happens only slightly (Fig.2.1a), and the number of centers which are able to participate in this process plays the decisive role. At concentrations that significantly exceed the limit of $10^{15} \mathrm{sm}^{-3}$ for negative R-centers, the solution of the system of equations is formally generally falls into negative area, which has no physical meaning (second column of the table 2.1). In a narrow region on the border of these concentrations probably an avalanche-like increase of the lifetime (Fig.2.1b). But only for positively charged $\mathrm{R}$-centers and negatively charged S-centers (second line, first column of the table 2.1).

The obtained results remove the existing contradictions. Properties of the S-centers are such that, while they are in the neutral state, they are able to capture an electron and a hole with the same capture cross section of $10^{-15} \mathrm{sm}^{2}$. As a result, the crystal are negatively and positively charged centers of the first class. However, since the material used is n-type, the mere predominance of electrons provides a more frequent seizures, and sensitizing occurs mainly according to the scenario in Fig.2.1b. The percentage ratio between the positively and negatively charged S-centers obtained for the first time. Perhaps this indicates that, analogous to a second class, the fast recombination centers also consist of several types.

\subsection{Modulation of LAC type with infrared light}

View of figures $2.1 \mathrm{a}$ and $2.1 \mathrm{~b}$ allows to predict lux-ampere dependence for both channels, tactile sensitizing. For fixed values of concentrations of centers of $N_{1}$ and $N_{2}$ in the case when the process involves positively charged $\mathrm{S}$ - centers (Fig.2.1a), the increase of intensity of photoexcitation causes approximately the same decrease in the lifetime. This should facilitate the formation of a more or less linear LAC.

Similarly, for negatively charged $\mathrm{S}$ - centers (Fig.2.1b), after tactile sensitizing (right of dotted line), with increasing levels of photoexcitation, the lifetime was decreased. The product of these quantities $n=f \cdot \tau_{n}$ remains approximately the same order of magnitude. In these circumstances we should expect lux-ampere dependence is close to linear, we indeed found experimentally [4].

In the bottom of the graph Fig.2.1b, in region $N_{2}$ « $N_{1}$ when sensitizing has not yet occurred, the lifetime increases with the intensity of photoexcitation. This should result converges lux-ampere characteristic. Change the formation mechanism of the LAC is further evidence of the prevalence in the crystal's centers, which have captured negative charge in compare with positively charged.

Such change of LAC is difficult to observe in dependence on the concentration of R-centers experimentally, because you will need very similar samples with different levels of doping or single crystal with sequentially adding in an admixture. Both ways are difficult to implement. In the first case, prevents the natural spread of parameters of crystals even grown in the same batch. And the second additive doping inevitably changes the previous distribution, we introduce impurities and properties are already made by other impurities (in our case at least, the S-centers). Crystal becomes inadequate.

However, it is possible to do otherwise [12,13]. If the intensity of infrared light is such that the number of incident photons is comparable and slightly lower concentration of R-centers, the light becomes modulating. The quantum of infrared radiation, absorbed on the centers of slow recombination, is inhibit for the population of their holes. As a result of effective concentration of R-centers, which are really involved in the process of tactile sensitizing becomes less. The share of such centers for the same crystal is the smaller, the greater the intensity of IR light, which impacted the crystal. 
Figure 2.2 shows a family of lux-ampere characteristics when excited by their own light $(\lambda=520$ $\mathrm{nm}$ ) of the crystal CdS with obviously present the effect of IR-quenching of photocurrent. As the parameter, was changed the intensity of the infrared light. Since the processes of tactile sensitizing can be superimposed on the influence of excited states of R-centers, applied a multiplier range of wavelengths from 900 to $1400 \mathrm{~nm}$. High light was monochromatic.

As can be seen from the figure 2.2, the effect of infrared light reduces the absolute value of the photocurrent (infrared quenching), but increases the degree of nonlinearity of the graph. For ease of comparison, the inset presents the dependence of the following values for the two extreme cases -off IR illumination (curve "a" corresponds to the curve 1 Fig.2.2) and the largest intensity of the additional infrared light (curve $\mathrm{b}$ corresponds to curve 3 in Fig.2.2).

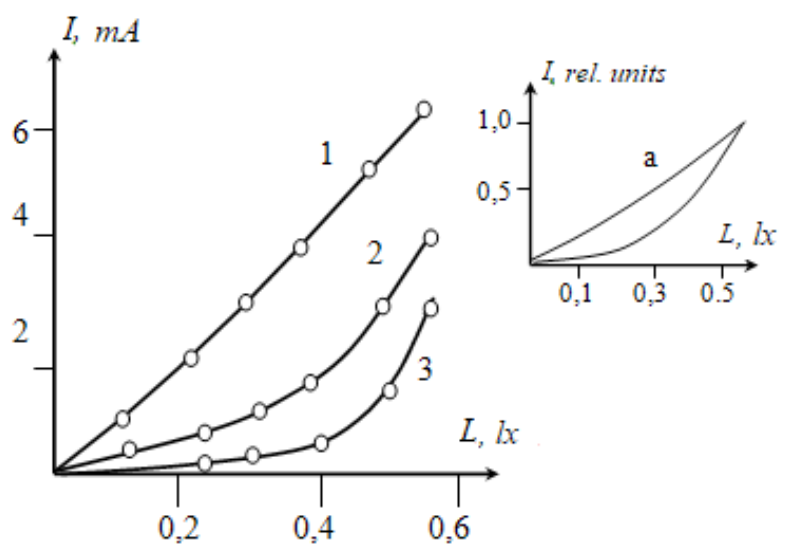

Fig. 2.2. The change of the photocurrent in the combined excitation with IR light: $1-0 ; 2-3,0 \cdot 10^{-3} ; 3-1,4 \cdot 10^{-2} \mathrm{Ix}$.

As originally effect of modulation of type LAC with infrared light requires the condition $N_{2} \gg N_{1}$, it can not be carried out for all crystals. However, if the phenomenon of the change of the lux-ampere characteristics from linear to converges which is not marked by A. Rose, after all is observed, it can serve as a good criterion of held tactile sensitizing of the sample, bypassing the estimation of the lifetime of carriers.

\section{References}

1. Новикова М.А. Особливості інфрачервоного гасіння фотоструму у напівпровідниках $\mathrm{CdS} . / /$ Работа - лауреат Областного конкурса (1 место) Малой академии наук, Областное территориальное отделение, Секция “Физика”. Одесса, 2005 г., с. 1 - 37.

2. M.A.Novikova Change of Photoelectric Properties of Semiconductors as a Tool for the Controlof Environmental Pollution by Extraneous Admixtures and IR-illumination.//Section of Environmental Science. Finalist of Intel International Science and Engineering Fair. USA, AZ, Phoenix, May 8-18. 2005.

3. Драгоев А.А., Затовская Н.П., Каракис Ю.Н., Куталова М.И. Управляемые электрическим полем датчики инфракрасного излучения.//Материалы $2 \mathrm{nd}$ International Scientific and Technical Conference "Sensors Electronicsand Microsystems Technology" Book of abstracts. 115. Секция IV "Радіаційні, оптичні, та оптоелектричні сенсори". Україна, Одеса, 26-30 червня 2006 р. “Астропринт”. 2006.

4. M.A.Novikova, Yu.N.Karakis, M.I. Kutalova Particularities of current transfer in the crystals with two types of Recombination centers. //Photoelectronics - 2005.n.14. -P. 58-61.

5. Каракис К.Ю. Релаксационные характеристики полупроводниковых кристаллов с ИК-гашением фототока.// Одесса, Работа - лауреат Областного конкурса (Ш место) Малой академии наук, Областное территориальное отделение, Секция “Физика”. Одесса 2001. c. 1-37.

6. Ю.Н. Каракис, Н.П. Затовская, В.В. Зотов, М.И., Куталова Особенности релаксации фототока в кристаллах сульфида кадмия с запорными контактами//1-а Українська наукова конференція з фізики напівпро- 
відників.- Одеса, 10-14 вересня 2002.

Тези доповідей. Т.2. - с.138

7. К.Ю. Каракис, В.А. Борщак, В.В. Зотов, М.М. Куталова Релаксационные характеристики кристаллов сульфида кадмия с ИКгашением.//Фотоэлектроника 2002.вып.11. - c.51-55.

8. A.A.Dragoev, Yu.N.Karakis, M.I. Kutalova Peculiarities in photoexcitation of carriers from deep traps.// Photoelectronics- 2006 - n. 15.-P. 5456

9. А.А.Драгоев Визначення квантового виходу інфрачервоного гасіння фототоку.//Робота - лауреат Областної сесії Малої Академії наук України. Одеське територіальне відділення. Секція “Фізика”. -Одеса 2006. c.32.

10. Ye.V. Brytavskyi, Yu. N. Karakis, M. I. Kutalova, G.G.Chemeresyuk Effects connected with interaction of charge carriers and R-centers basic and exited states./Photoelectronics. -2009 . $-\mathrm{n}$. 18.-P. $84-87$.
11. E.V.Britavsky,

Y.N.Karakis, M.I.Kutalova, G.G.Chemeresyuk On the charge state of rapid and slow recombination centers in semiconductors//Photoelectronics.-2008. - n.17.2009. - n. 18-P. $65-69$.

12. Бритавский Е.В. Эффект модулирования вида люксамперной характеристики инфракрасным светом //63-я отчётная студенческая научная конференция, посвящённая 143-й годовщине Одесского национального университета имени И.И. Мечникова. Физический факультет. Секция физики полупроводников и диэлектриков. 23 - 24 апреля - 2008. Тезисы докладов - С. $52-53$.

13. G.G.Chemeresyuk, Ie. V. Brytavskyi, Yu. N. Karakis (Ukraine) Infrared radiation sensor with selective controlled sensitiviti// The Ninth International Conference "Correlation Optics 2009" - Chernivtsi National UniversityChernivtsi, Ukraine. September 20 - 24. - 2009. Poster Session. Session 2 - D-2.

This article has been received within April 2017.

UDC 621.315 .592

N. S. Simanovych, Ye. V. Brytavskyi, M. I. Kutalova, V. A. Borshchak, Y. N. Karakis

\section{THE STUDY OF HETEROGENEOUS SENSITIZED CRYSTALS OF CADMIUM SULFIDE. PART I. ABOUT CHARGE OF THE CENTERS RECOMBINATION}

\section{Summary}

The photovoltaic properties of CdS crystals with combined alloying have been investigated. An analytical expression for the dependence of the coefficient of damping of the intensities of exciting and quenching light has been received. For the first time the concentration of fast recombination centers has been estimated.

The charge state of S - and R- centersis expected. The exclusive method of decision of the system of equalizations is thus created. Modulation of LAC is shown by IR light.

Key words: oefficient of damping, CdS, IR light. 
Н. С. Сіманович, Е. Д. Бритавський, М. І. Куталова, В. А. Борщฺак, Ю. М. Каракіс

\section{ДОСЛІДЖЕННЯ НЕОДНОРІДНО ЗЧУВСТВЛЕННИХ КРИСТАЛІВ СУЛЬФІДУ КАДМІЯ. ЧАСТИНА І. ПРО ЗАРЯДОВИЙ СТАН ЦЕНТРІВ РЕКОМБІНАЦІї}

\section{Резюме}

Досліджені фотоелектричні властивості кристалів $\mathrm{CdS}$ з комбінованим легуванням. Отримано аналітичний вираз для залежності коєфіціента гасіння от інтенсивностей збуджующего і гасящего світла. Вперше оцінена концентрація центрів швидкої рекомбінації.

Розрахован зарядовий стан S- i R-центрів. При цьому створено ексклюзивний метод вирішення системи рівнянь. Продемонстрована модуляція ЛАХ інфрачервоним світлом.

Ключові слова: коєфіціент гасіння, сульфід кадмію, інфрачервоне світло.

УДК 621.315 .592

Н. С. Симанович, Е. Д. Бритавский, М. И. Куталова, В. А. Борщзак, Ю. Н. Каракис

\section{ИССЛЕДОВАНИЕ НЕОДНОРОДНО ОЧУВСТВЛЁННЫХ КРИСТАЛЛОВ СУЛЬФИДА КАДМИЯ. ЧАСТЬ І. О ЗАРЯДОВОМ СОСТОЯНИИ ЦЕНТРОВ РЕКОМБИНАЦИИ}

\section{Резюме}

Исследованы фотоэлектрические свойства кристаллов $\mathrm{CdS}$ с комбинированным легированием. Получено аналитическое выражение для зависимости коэффициента гашения от интенсивностей возбуждающего и гасящего света. Впервые оценена концентрация центров быстрой рекомбинации.

Рассчитано зарядовое состояние S- и R-центров. При этом создан эксклюзивный метод решения системы уравнений. Продемонстрирована модуляция ЛАХ инфракрасным светом.

Ключевые слова: коэффициент гашения, сульфид кадмия, инфракрасный свет. 